\title{
The changing face of gestational diabetes: the effect of the shift from risk factor-based to comprehensive screening
}

\author{
Sanna Koivunen ${ }^{1,2}$, Eero Kajantie ${ }^{1,3,4}$, Annukka Torkki ${ }^{1,2}$, Aini Bloigu², \\ Mika Gissler ${ }^{5}$, Anneli Pouta ${ }^{2}$ and Marja Vääräsmäki ${ }^{1,2}$
}

1Department of Obstetrics and Gynaecology and MRC Oulu, Oulu University Hospital and University of Oulu, PO Box 23, 90029 OYS Oulu, Finland, ${ }^{2}$ Child and Adolescent Health and Wellbeing Unit, National Institute for Health and Welfare, PO Box 23, 90029 OYS Oulu, Finland, ${ }^{3}$ Chronic Disease Prevention Unit, National Institute for Health and Welfare, Helsinki, Finland, ${ }^{4}$ Children's Hospital, Helsinki University Hospital and University of Helsinki, Helsinki, Finland and ${ }^{5}$ Information Department, National Institute for Health and Welfare, Helsinki, Finland and Nordic School of Public Health, Gothenburg, Sweden

Correspondence should be addressed to S Koivunen

Email

sanna.koivunen@oulu.fi

\begin{abstract}
Objective: To evaluate the effect of the change in the gestational diabetes (GDM) screening policy from risk-factor based to comprehensive screening on the prevalence and type of GDM and characteristics of GDM pregnancies.

Design: Population-based register study in Finland. Subjects were GDM women who gave birth before $(2006, n=5185)$ and after $(2010, n=6683)$ the policy change. All the other women in those years without pre-pregnancy diabetes acted as controls (51 759 and 52398 respectively).

Methods: GDM women with singleton pregnancy were identified through The Finnish Medical Birth Register by abnormal oral glucose tolerance test or initiation of insulin. Main outcome measures were prevalence of GDM (total and insulin/ diet-treated), and caesarean section rate.

Results: The proportion of screened mothers increased from 27.5 to $51.3 \%$ and the total prevalence of GDM from 9.1 to $11.3 \%$. This increase consisted mainly of diet-treated mothers, while the number and proportion of insulin-treated mothers decreased $(21.8 \%$ vs $13.3 \%, P<0.001)$. The proportion of primiparous women increased $(34.5-39.4 \%, P<0.0001)$ and mean pre-pregnancy BMI decreased (28.6-28.2, $P<0.001)$. The overall caesarean section rate remained the same but increased among women with GDM (20.8-22.1\%) adjusted odds ratios being $1.22(95 \% \mathrm{Cl} 1.14,1.31)$ during comprehensive and $1.10(95 \% \mathrm{Cl} 1.02,1.19)$ during risk factor-based screening.

Conclusions: The shift to comprehensive screening led to a significant increase in women with GDM, who were more often primiparous and had a lower BMI. Comprehensive screening did not perform better in diagnosing women needing insulin treatment.
\end{abstract}

\section{Introduction}

Gestational diabetes mellitus (GDM) is a common pregnancy-related disorder, which, depending on screening policies, diagnostic cutoffs and study populations, affects $2-24 \%$ of pregnancies $(1,2,3)$. Its detection offers benefits to both mother and her offspring during and immediately after pregnancy $(4,5,6)$. In the long term, mothers with a history of GDM are more likely to develop type 2 diabetes (c) 2015 European Society of Endocrinology Printed in Great Britain and other metabolic disturbances $(7,8,9)$. In addition, their offspring have a higher risk of obesity and abnormal glucose metabolism $(4,10)$. While these associations have been widely documented, the challenge is to detect GDM in order to identify these high-risk groups.

Although there is increasing awareness of the impact of GDM on maternal and fetal health, there is no 
consensus concerning its screening policy and diagnostic criteria. Basically, the diagnostic criteria of GDM have been set according to their ability to identify mothers at risk of subsequent diabetes $(11,12)$. Their ability to predict neonatal outcomes was first employed to define diagnostic criteria by the International Association of Diabetes in Pregnancy Study Groups (IADPSG). By using the data obtained from a large multicenter Hyperglycemia and Adverse Pregnancy Outcomes (HAPO) study (13), the IADPSG suggested universal screening and uniform diagnostic criteria using a $75 \mathrm{~g}$ oral glucose tolerance test (OGTT) at 24-28 weeks of gestation (14).

Screening guidelines vary from no routine to universal screening. In Finland, GDM screening was limited to women with risk factors until 2008. However, up to half of women with GDM have been found to have no risk factors, and thus to go undiagnosed during risk factorbased screening (15). When new national Current Care Guidelines to screen and diagnose GDM were introduced in Finland in 2008, in contrast to previous policy, it was recommended that all women except those with very low GDM risk should be tested via $75 \mathrm{~g}$ OGTT (16). These guidelines were expected to increase the numbers of both screened women and those diagnosed with GDM.

The aim of the present study was to evaluate the effect of the change in the GDM screening policy on the prevalence and type of GDM, maternal characteristics, and the course of pregnancy and delivery.

\section{Subjects and methods}

\section{The Finnish Medical Birth Register}

The data were based on the Finnish Medical Birth Register (MBR), which includes data on the course and complications of pregnancy, delivery, and perinatal health of the newborn. All pregnancies resulting in a live born infant or stillbirth at a gestational age of $\geq 22$ weeks or weighing $\geq 500 \mathrm{~g}$ are reported to the MBR. For each delivery in Finland, a structured form for the MBR is completed by the delivery hospital within 7 days after delivery.

The data are checked at the MBR and the hospitals are contacted to correct missing or supposedly incorrect information. Data are completed by linkage to the Central Population Register on live births and to cause-of-death data compiled by Statistics Finland on stillbirths and early neonatal deaths. The coverage of the register is complete, and in general, the quality of the data is high $(17,18)$. The study was approved by the regional Ethics Committee in Northern Ostrobothnia Hospital District, Number 2008/43, date of approval 2008-6-19.

\section{Study population}

Since 2004, the MBR has also included information on whether an OGTT was performed, whether it was abnormal (the criteria are described in the following section) and whether insulin treatment was initiated. In the present study, a woman was defined to have GDM if she was recorded to have an abnormal OGTT result or initiation of insulin therapy during pregnancy. After exclusion of multiple births and mothers with pre-existent type 1 or type 2 diabetes, 5185 (9.1\%) women in 2006 and $6683(11.3 \%)$ in 2010 fulfilled the GDM criteria. All other non-GDM women served as controls (51 759 in 2006 and 5398 in 2010; Fig. 1). Preterm infants with abnormally high birth weight for length of gestation $(<37$ weeks and $>3$ s.D. according to Finnish standards (19) were excluded from birth weight analyses $(n=35)$.

\section{Screening and treatment for GDM}

Until 2008, GDM risk factor-based screening was used in Finland (risk factors are shown in Table 1). According to the new national Current Care Guidelines launched in 2008, all women except those with very low risk should be screened for GDM (16). In both time periods, the screening of GDM was performed and diagnosis set by a standard $2 \mathrm{~h} 75 \mathrm{~g}$ OGTT with samples obtained at baseline after overnight fast and at 1 and $2 \mathrm{~h}$ after the glucose load. The test was mainly performed between the 24th and 28th weeks of gestation. In both screening policies, it was recommended for an OGTT to be performed for the first time between the 12th and 16th

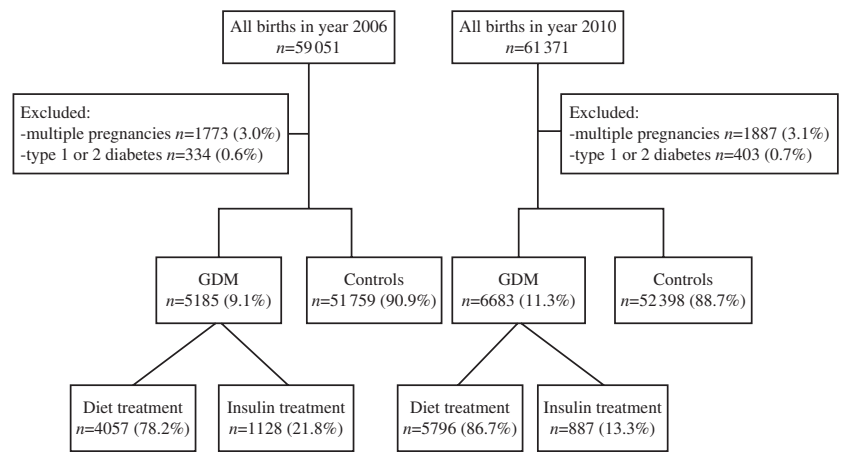

Figure 1

Flow chart of the study. 
Table 1 Comparison of risk-factor based and comprehensive screening.

\begin{tabular}{|c|c|c|c|c|}
\hline Screening method & Indication for screening & $\begin{array}{c}\text { OGTT } \\
\text { performed }(n)(\%)\end{array}$ & $\begin{array}{c}\text { Gestational } \\
\text { diabetes } \\
\text { diagnosed }(n)(\%)\end{array}$ & $\begin{array}{l}\text { Number needed to } \\
\text { screen GDM } \\
\text { (OGTT/GDM) }\end{array}$ \\
\hline $\begin{array}{l}\text { Risk factor-based } \\
\text { screening }(2006)\end{array}$ & $\begin{array}{l}\text { Risk factor-based screening } \\
\text { Prior GDM } \\
\text { Overweight (BMI }>25 \mathrm{~kg} / \mathrm{m}^{2} \text { ) } \\
\text { Glucosuria } \\
\text { Age over } 40 \text { years } \\
\text { Previous macrosomic offspring } 4500 \mathrm{~g} \text { or more) } \\
\text { Suspected macrosomia in the current pregnancy }\end{array}$ & $15688(27.5 \%)$ & $5185(9.1 \%)$ & 3.13 \\
\hline $\begin{array}{l}\text { Comprehensive } \\
\text { screening (2010) }\end{array}$ & $\begin{array}{l}\text { All women except those with very low GDM risk } \\
\text { Primiparous: age }<25 \text { years, BMI }<25 \mathrm{~kg} / \mathrm{m}^{2} \text {, } \\
\text { no family history of diabetes } \\
\text { Multiparous: age }<40 \text { years, BMI }<25 \mathrm{~kg} / \mathrm{m}^{2} \text {, } \\
\text { no previous macrosomic babies }\end{array}$ & $30372(51.4 \%)$ & $6683(11.3 \%)$ & 4.71 \\
\hline
\end{tabular}

The OGTT test is mainly performed between the 24th and 28th week of gestation. In both screening policies, an OGTT is recommended for the first time between the 12th and 16th gestational week for high-risk groups (before 2008 prior GDM; after 2008: prior GDM, BMI > 35, polycystic ovary syndrome with insulin resistance), and if this test was normal, to be repeated at 24-28 weeks.

weeks of gestation for high-risk groups (before 2008: prior GDM; after 2008: prior GDM, BMI >35, polycystic ovary syndrome with insulin resistance). If this test was normal, it would then be repeated between the 24th and 28th weeks of gestation.

GDM was diagnosed during both screening periods if the venous plasma glucose concentration was $5.3 \mathrm{mmol} / 1$ or more at baseline, $10.0 \mathrm{mmol} / 1$ or more at $1 \mathrm{~h}$, or $8.6 \mathrm{mmol} / \mathrm{l}$ or more at $2 \mathrm{~h}$ after the glucose load. Before 2008 , the cutoffs were specified in an expert statement given in 1993. After 2008, when the cutoff was explicitly stated in the new national Current Care Guidelines, these cutoffs were uniformly adopted to our knowledge by virtually all service providers. During both periods, the diagnosis of GDM was based on one or more abnormal value in OGTT.

After the diagnosis of GDM, the patients received dietary and lifestyle counselling and began self-monitoring of glucose concentrations. According to the prevailing treatment guidelines, insulin therapy was initiated if plasma glucose concentrations exceeded the target levels repeatedly (before 2008: $5.3 \mathrm{mmol} / \mathrm{l}$ fasting and $6.7 \mathrm{mmol} / 1 \mathrm{l} 1.5 \mathrm{~h}$ postprandial; after 2008: 5.5 and $7.8 \mathrm{mmol} / 1 \mathrm{~h}$ postprandial). The use of oral glycemic agents was occasional and not recommended by the guidelines.

\section{Definitions}

The outcome measures, including gestational age at birth, birth weight, and data on pregnancy-related states and complications such as preeclampsia were obtained from the MBR. The diagnoses of hypertensive pregnancy disorders were based on recorded ICD-10 codes (from O10 to O16). Maternal age was defined as the mother's age at the time of delivery. BMI was calculated as the mother's pre-pregnancy weight divided by the square of her height. Birth weight S.D. score, relative to length of gestation and sex was calculated based on Finnish standards (19). Antenatal visits included the number of all visits to maternal welfare clinics or the delivery hospital during pregnancy. Special care visits included only visits to the delivery hospital.

Socioeconomic status was defined using the occupation reported to the MBR. Coding was based on national standards published by Statistics Finland (selfemployed persons, upper-level employees with administrative, managerial, professional and related occupations, lower-level employees with administrative and clerical occupations, manual workers, students, pensioners and others) (20). The socioeconomic groups were divided into four different categories, as follows: i) upper-level employees with administrative, managerial, professional and related occupations, ii) lower-level employees with administrative and clerical occupations, iii) manual workers, and iv) others, including stay-at-home mothers, students, pensioners, and self-employed persons. In terms of smoking, women were categorized as non-smokers, those who stopped smoking in first trimester, smokers after the first trimester and no information. Of Finnish women aged 15-49 years, 94.7\% are of Finnish ancestry (21). 


\section{Outcomes}

The primary outcome was the difference in the prevalence and type of GDM. Secondary outcomes included changes in maternal characteristics, including age, parity, and pre-pregnancy BMI, as well as in the induction and mode of delivery.

\section{Statistical analysis}

All statistical analyses were carried out using the SPSS 21 statistical package. Categorical variables were reported as frequencies (\%) and continuous using mean (s.D.) or median (range). Pearson's $\chi^{2}$-test was used to compare the difference in proportions, while the independent sample $t$-test was used to compare the difference in the means. A two-sided $P$ value of $<0.05$ was considered statistically significant. Logistic regression was used to calculate odds ratios (ORs) and 95\% CIs for the risk of development of outcomes associated with GDM in different study periods. Mean differences with 95\% CI were calculated using linear regression. All logistic regression results were adjusted for maternal age, parity, and pre-pregnancy BMI. Interactions were tested by adding the product term between the two variables of interest into the regression model. Additional analyses adjusted further for socioeconomic status and maternal smoking during pregnancy.

\section{Results}

\section{The study population}

The total number of all deliveries in Finland was 59051 in 2006 and 61371 in 2010 (Fig. 1). Of these, 56944 and 59081 respectively, were singleton pregnancies of mothers without pre-pregnancy type 1 or type 2 diabetes and were included in the present study. The mean ages of all women giving birth in 2006 and 2010 were 29.5 and 29.6 years respectively. Over $40 \%$ of women were primiparous in both years (Table 1). The pre-pregnancy BMI increased significantly in the whole study population, from 24.1 (s.D. 4.6) in 2006 to 24.3 (s.D. 4.8) in 2010.

\section{The effect of the change in screening policy}

The proportion of mothers undergoing OGTT increased from $27.5 \%$ under the risk-factor based screening method to $51.4 \%$ under comprehensive screening (Table 1).
Together with this increase, the prevalence of GDM rose from 9.1 to $11.3 \%$. Of all screened mothers, the number needed to screen for one GDM diagnosis was 3.13 during risk factor-based and 4.71 during comprehensive screening. Positive predictive values were $27.3 \%$ for risk factor-based screening and $20.8 \%$ for comprehensive screening.

\section{Maternal characteristics}

The baseline characteristics of the study population are presented in Table 2. During comprehensive screening, GDM women were more often primiparous (39.4 vs $34.5 \%)$, had lower pre-pregnancy BMI (28.2 vs 28.6 $\mathrm{kg} / \mathrm{m}^{2}$ ) and were more often normal weight (27.0 vs $32.6 \%)$ than during screening based on risk factors. The mean age and socioeconomic status were similar in the GDM groups in both study years.

\section{Antenatal visits}

Between 2006 and 2010, the mean number of all antenatal follow-up visits decreased in both the GDM and control groups, although the decrease was more evident in GDM mothers (Table 2). In addition, the mean number of hospital outpatient visits decreased in both the GDM and control groups. However, as a result of the growth in GDM prevalence, the total number of both all antenatal and special health care visits in GDM mothers increased (Table 2).

\section{Delivery}

The proportion of induced deliveries increased both in GDM (25.7-28.3\%) and non-GDM women (14.9-16.9\%; Table 2), and the increase was similar for both groups $(P$ value for interaction GDM $\times$ year of birth: unadjusted $P$ value $0.6, P$ value adjusted for maternal age, parity, and pre-pregnancy BMI 0.7; Table 3). The caesarean section rate increased in the GDM group from 20.8 to $22.1 \%$, but decreased in the non-GDM mothers (15.1 to $14.7 \%$, respectively; Table 2). The total caesarean section rate remained similar (17.1 and $17.1 \%$ respectively). The adjusted ORs for caesarean section for GDM as compared with controls were 1.10 (risk factor-based screening) and 1.22 (comprehensive screening). $P$ values for interaction between the effects of screening method and GDM on caesarean section were 0.018 (adjusted) and 0.052 (unadjusted) (Table 3). 


\section{Birth weight}

During risk factor-based screening, infants of GDM mothers had 0.37 s.D. higher birth weight than infants of control mothers. During comprehensive screening, this difference was 0.26 s.D. After adjustment for maternal age, parity, and pre-pregnancy BMI, the mean difference of the birth weight s.D. score decreased between the study periods from 0.20 to 0.11 s.D. This decrease corresponds to $50 \mathrm{~g}$ birth weight at term (Table 3).

Table 2 Characteristics of the mothers with and without gestational diabetes during risk factor based (2006) and comprehensive (2010) screening.

\begin{tabular}{|c|c|c|c|c|c|c|c|}
\hline \multirow[b]{2}{*}{ Characteristic } & \multicolumn{3}{|c|}{ GDM } & \multicolumn{3}{|c|}{ Controls } & \multirow{2}{*}{$\begin{array}{c}\text { GDM } \times \text { year } \\
P \text { for } \\
\text { interaction }^{a}\end{array}$} \\
\hline & 2006 & 2010 & $P$ value & 2006 & 2010 & $P$ value & \\
\hline$n$ & $5185(9.1 \%)$ & $6683(11.3 \%)$ & & $51759(90.9 \%)$ & $52398(88.7 \%)$ & & \\
\hline Maternal age (years) & $31.1(5.7)$ & $31.0(5.5)$ & 0.526 & $29.3(5.4)$ & $29.4(5.3)$ & 0.007 & 0.140 \\
\hline Pre-pregnancy BMI $\left(\mathrm{kg} / \mathrm{m}^{2}\right)$ & $28.6(5.8)$ & $28.2(6.1)$ & $<0.0001$ & $23.7(4.3)$ & $23.8(4.4)$ & $<0.0001$ & $<0.0001$ \\
\hline BMI 18.5-24.9 & $1340(27.0 \%)$ & $2102(32.6 \%)$ & $<0.0001$ & $33358(70.5 \%)$ & $33420(68.7 \%)$ & $<0.0001$ & $<0.0001$ \\
\hline BMI 25-29.9 & $1790(36.1 \%)$ & $2198(34.1 \%)$ & 0.023 & $9736(20.6 \%)$ & $10509(21.6 \%)$ & $<0.0001$ & $<0.0001$ \\
\hline $\mathrm{BMI}>30$ & $1827(36.9 \%)$ & $2154(33.4 \%)$ & $<0.0001$ & $4205(8.9 \%)$ & $4733(9.7 \%)$ & $<0.0001$ & $<0.0001$ \\
\hline \multicolumn{8}{|l|}{ Parity, $n(\%)$} \\
\hline 1 & $1788(34.5 \%)$ & $2635(39.4 \%)$ & $<0.0001$ & $22229(43.1 \%)$ & $22293(42.5 \%)$ & 0.085 & $<0.0001$ \\
\hline 2 & $1775(34.2 \%)$ & $2180(32.6 \%)$ & 0.064 & $17172(33.2 \%)$ & $17693(33.8 \%)$ & 0.044 & 0.017 \\
\hline 3 & $901(17.4 \%)$ & $1052(15.7 \%)$ & 0.017 & $7368(14.2 \%)$ & $7513(14.3 \%)$ & 0.634 & 0.016 \\
\hline 4 & $379(7.3 \%)$ & $434(6.5 \%)$ & 0.081 & $2555(4.9 \%)$ & $2430(4.6 \%)$ & 0.024 & 0.433 \\
\hline$\geq 5$ & $342(6.6 \%)$ & $382(5.7 \%)$ & 0.047 & $2281(4.4 \%)$ & $2467(4.7 \%)$ & 0.026 & 0.008 \\
\hline \multicolumn{8}{|l|}{ Socioeconomic status $(n)(\%)$} \\
\hline Upper-level clerical officials ${ }^{b}$ & $791(17.7 \%)$ & $954(18.7 \%)$ & 0.180 & $9519(21.6 \%)$ & $8526(22.1 \%)$ & 0.072 & 0.463 \\
\hline Lower-level clerical officials ${ }^{c}$ & $1955(43.6 \%)$ & $2219(43.5 \%)$ & 0.919 & $17685(40.1 \%)$ & $15727(40.7 \%)$ & 0.051 & 0.464 \\
\hline Manual workers & $896(20.0 \%)$ & $966(19.0 \%)$ & 0.196 & $7232(16.4 \%)$ & $6103(15.8 \%)$ & 0.024 & 0.662 \\
\hline Others $^{\mathrm{d}}$ & $838(18.7 \%)$ & $958(18.8 \%)$ & 0.910 & $9696(22.0 \%)$ & $8246(21.4 \%)$ & 0.034 & 0.449 \\
\hline \multicolumn{8}{|l|}{ Smoking $(n)(\%)$} \\
\hline No & $4237(81.7 \%)$ & $5385(80.6 \%)$ & 0.116 & $42732(82.6 \%)$ & $43458(82.9 \%)$ & 0.100 & 0.043 \\
\hline Quit at first trimester & $220(4.2 \%)$ & $400(6.0 \%)$ & $<0.0001$ & $1963(3.8 \%)$ & $2805(5.4 \%)$ & $<0.0001$ & 0.989 \\
\hline Continued after first trimester & $641(12.4 \%)$ & $791(11.8 \%)$ & 0.382 & $5529(10.7 \%)$ & $4976(9.5 \%)$ & $<0.0001$ & 0.178 \\
\hline No information & $87(1.7 \%)$ & $107(1.6 \%)$ & 0.743 & $1535(3.0 \%)$ & $1155(2.2 \%)$ & $<0.0001$ & 0.089 \\
\hline \multicolumn{8}{|l|}{ Treatment: } \\
\hline Insulin & $1128(21.8 \%)$ & $887(13.3 \%)$ & $<0.0001$ & & & & \\
\hline Diet & $4057(78.2 \%)$ & $5796(86.7 \%)$ & $<0.0001$ & & & & \\
\hline Antenatal visits (total number) & 96449 & 111583 & & 828583 & 782619 & & \\
\hline $\begin{array}{l}\text { Antenatal visits/mother, } \\
\text { mean (s.D.) }\end{array}$ & $18.8(6.7)$ & $17.0(4.7)$ & $<0.0001$ & $16.4(5.2)$ & $15.4(4.2)$ & $<0.0001$ & $<0.0001$ \\
\hline $\begin{array}{l}\text { Special health care visits } \\
\text { (total number) }\end{array}$ & 24262 & 28950 & & 132101 & 135401 & & \\
\hline $\begin{array}{l}\text { Special health care } \\
\text { visits/mother, mean (s.D.) }\end{array}$ & $4.7(3.3)$ & $4.5(3.0)$ & 0.001 & $2.6(2.4)$ & $2.7(2.3)$ & $<0.0001$ & $<0.0001$ \\
\hline $\begin{array}{l}\text { Gestational hypertension or } \\
\text { preeclampsia }\end{array}$ & $422(8.1 \%)$ & $608(9.1 \%)$ & 0.066 & $2144(4.1 \%)$ & $2282(4.4 \%)$ & 0.089 & 0.341 \\
\hline Induction of labor & $1334(25.7 \%)$ & $1893(28.3 \%)$ & 0.002 & $7712(14.9 \%)$ & $8875(16.9 \%)$ & $<0.0001$ & 0.647 \\
\hline Gestational age (mean) (s.D.) & $39.6(1.6)$ & $39.6(1.6)$ & 0.328 & $39.8(1.8)$ & $39.9(1.8)$ & $<0.0001$ & 0.036 \\
\hline Birth weight, grams, mean (s.D.) & 3695 (434) & 3635 (434) & $<0.0001$ & 3516 (434) & 3497 (434) & $<0.0001$ & $<0.0001$ \\
\hline \multicolumn{8}{|l|}{ Type of delivery } \\
\hline Vaginal, non-instrumental & $3702(71.4 \%)$ & $4610(69.3 \%)$ & 0.005 & $39386(76.1 \%)$ & $39754(75.9 \%)$ & 0.619 & 0.013 \\
\hline Vaginal, instrumental & $386(7.4 \%)$ & $573(8.6 \%)$ & 0.011 & $4267(8.2 \%)$ & $4584(8.7 \%)$ & 0.005 & 0.223 \\
\hline Caesarean section & $1076(20.8 \%)$ & $1469(22.1 \%)$ & 0.045 & $7811(15.1 \%)$ & $7696(14.7 \%)$ & 0.169 & 0.031 \\
\hline $\begin{array}{l}\text { Hospital stay of mother in days, } \\
\text { mean (s.D.) }\end{array}$ & $2.5(1.76)$ & $2.2(1.39)$ & $<0.0001$ & $2.2(1.5)$ & $1.9(1.3)$ & $<0.0001$ & 0.103 \\
\hline $\begin{array}{l}\text { The numbers are } n(\%) \text { or mean (s. } \\
\text { a Interaction between the effects of } \\
\text { bUpper-level officials with administ } \\
\text { 'Lower-level officials with administ } \\
{ }^{\mathrm{d}} \text { Students, pensioners, self-employe }\end{array}$ & aric cend & $\begin{array}{l}\text { essional, anc } \\
\text { ations. }\end{array}$ & derat 190 & ons. & & & \\
\hline
\end{tabular}




\section{The changes in treatment of GDM}

Between years 2006 and 2010, both the proportion and absolute number of insulin-treated GDM women reduced significantly, from 1128 to 887 ( 21.8 to $13.3 \%$ of all GDM mothers, Table 4). Regardless of the screening policy, insulin-treated GDM mothers were older, had higher prepregnancy BMI, and were more often parous than those with diet treatment (Table 4). During comprehensive screening, insulin-treated mothers had significantly higher pre-pregnancy BMI than during the previous study period (30.2 vs 28.8 respectively). Socioeconomic status was unrelated to insulin treatment during both screening periods.

Insulin-treated mothers attended a maternal welfare clinic or hospital outpatient care more often than diettreated mothers in both screening periods (Table 4). In addition, induced deliveries and caesarean sections were more frequent among insulin- than diet-treated mothers, the proportions being higher during comprehensive screening (Table 4).

\section{Discussion}

The shift in GDM screening from a risk factor-based to a comprehensive policy led to a significant increase in the prevalence of gestational diabetes, which was due to the increased number of mothers who could be treated with diet. Unexpectedly, both the proportion and total number of insulin-treated women decreased significantly. Comprehensive screening seems to identify more primiparous and normal weight GDM women, but is unlikely to be more efficient than risk factor-based screening when it comes to identifying women who need insulin, which represents an essential risk group for maternal and perinatal complications. Although the number of antenatal visits per woman decreased both at the primary and secondary level, the significant increase in the number of GDM women created a rising burden for the healthcare system.

A risk factor-based policy has been considered as reliable and less expensive than a universal approach to screening GDM at the population level. However, in previous studies, $20-50 \%$ of women with GDM had no risk factors for this condition $(1,15,22,23)$. One reason for this might be the nature of the risk factors: Many of them are based on previous pregnancy history, including prior GDM or previous macrosomic newborns, but these factors do not apply to primiparous women. The increased proportion of primiparous women diagnosed by 
$\mid$ |บ|

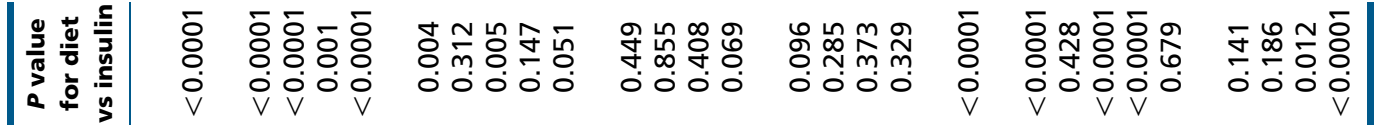

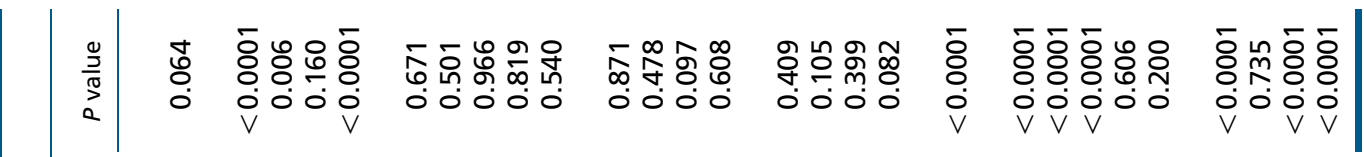

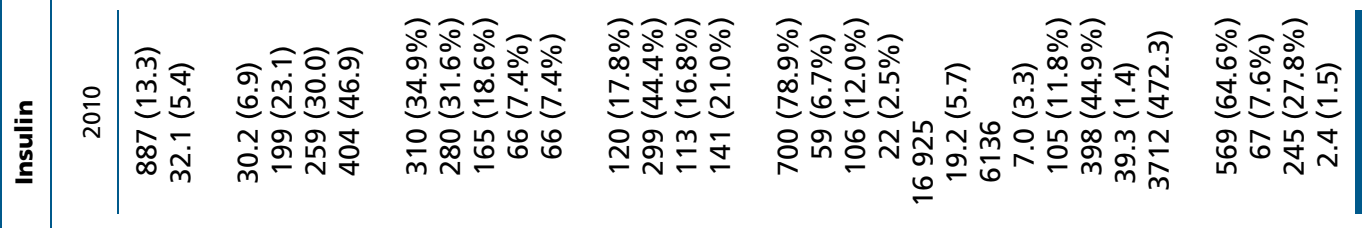

.

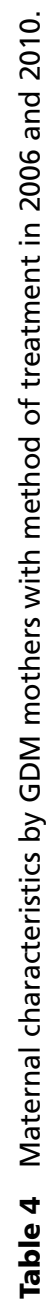

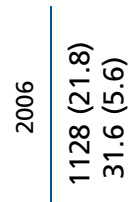

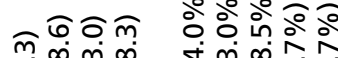

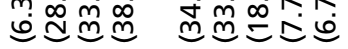

$\stackrel{\infty}{\infty} \underset{m}{N} \frac{b}{m} \frac{\infty}{q}$

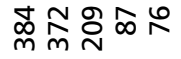

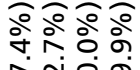

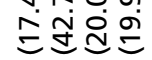

ㅊํํำ

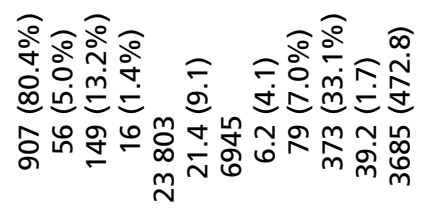

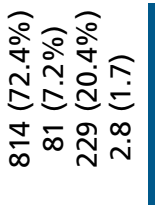

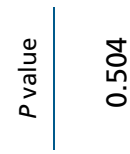

î̀

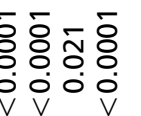

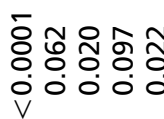

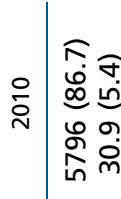

ํำตุ ㅇํㅇํำ

ம்

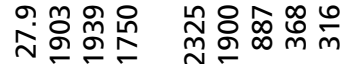

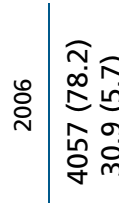

ํิดำ

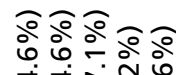

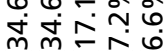

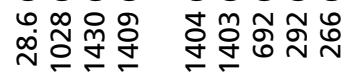

วิํํㅇำ

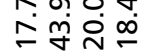

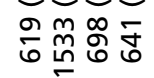

वेळ)

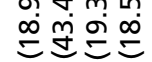

㠃金命亦

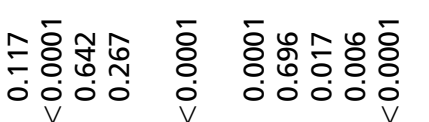

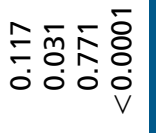

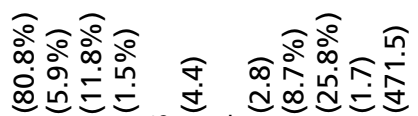

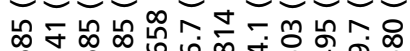
ป

वेळà

ód

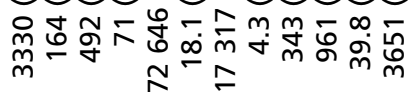
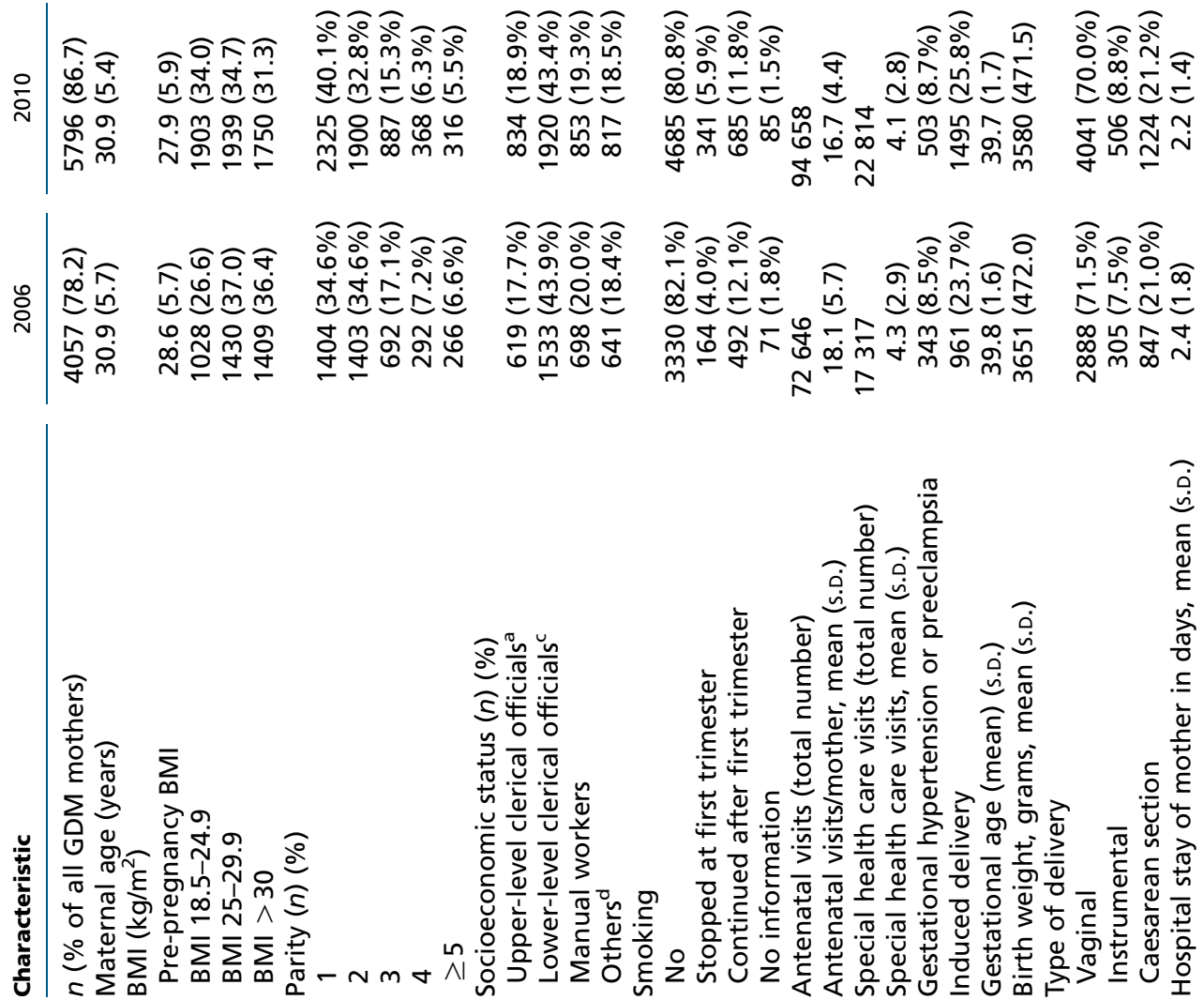

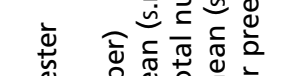

离.

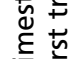

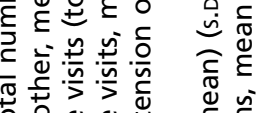

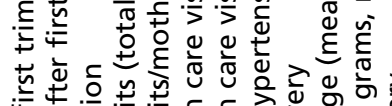

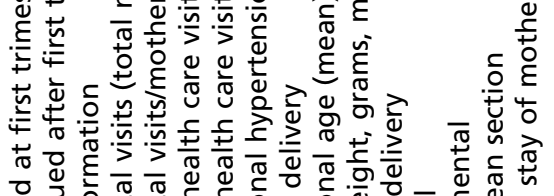

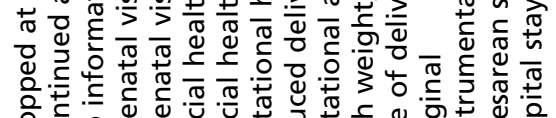

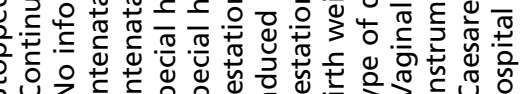

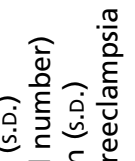

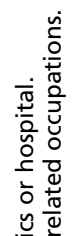

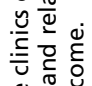

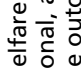

要, 음

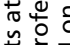

娄立施

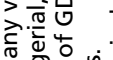

II O)

宩

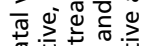

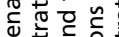

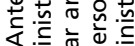

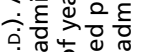

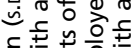

क्षे

t.

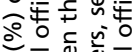

厂

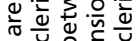

竞

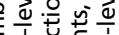

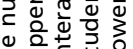


comprehensive screening may reflect this. Another reason might be the change in the definition of risk factors: during comprehensive screening, OGTT was recommended if there was a family history of diabetes, even in women who would otherwise have been exempted from the test because of a very low risk of GDM. Nowadays, every third GDM woman has first-degree relative with diabetes (23). As the prevalence of type 2 diabetes increases in Finland $-15.7 \%$ of men and $11.2 \%$ of women have been diagnosed the disease (24)- family history is also considerable as a screening indication.

Although the total number of GDM mothers increased between the study periods, the proportion and the absolute number of women treated with insulin decreased significantly. Uniform guidelines, together with revised uniform cutoff levels for insulin treatment, may be important reasons for this change: target levels for fasting glucose concentration rose from 5.3 to $5.5 \mathrm{mmol} / \mathrm{l}$, and those for postprandial glucose from $6.71 .5 \mathrm{~h}$ after meal to $7.8 \mathrm{mmol} / 1 \mathrm{~h}$ after meal, which may contribute to the decrease of the amount of insulin treated GDM women. The change to measure postprandial glucose concentration $1 \mathrm{~h}$ instead $1.5 \mathrm{~h}$ after meal was based on a national consensus in the development of the national Current Care Guidelines and is likely to identify a similar amount of women for insulin treatment (25). On the other hand, the decrease may also reflect successful diet counseling according to the uniform guidelines. Insulin-treated GDM mothers were older, had higher pre-pregnancy BMI values and were less often primiparous than diet-treated women during the two study periods. The hypertensive disorders, need for delivery inductions and caesarean sections cumulated in this group, especially under comprehensive screening. Therefore, women with insulin treatment belong to a group requiring special antenatal care, as well as care during delivery.

The number of women screened to find one woman with GDM was higher during comprehensive than risk factor-based screening. However, these rates are difficult to compare, as a large number of women with GDM likely remained undiagnosed during selective screening. In this study setting, it is not possible to evaluate the presence and significance of risk factors in different study years. While the risk of having GDM after pregnancy with normal glucose metabolism is low, at about 1\% (26), it might be worth considering the use of comprehensive screening during the first pregnancy and risk factor-based screening thereafter. However, this policy merits further evaluation.
The change in the screening protocol induced a substantial increase of performed OGTTs, diagnoses and a need for counseling and follow-up. Because Finland has low perinatal mortality and advanced perinatal care, the effect of intensive screening on short-term perinatal outcomes may be difficult to detect. The recent UK NICE Guideline of Diabetes in Pregnancy includes a detailed cost-effectiveness analysis and concludes that there is insufficient evidence to demonstrate that alternative screening strategies are more cost effective than risk factor screening recommended by earlier NICE guidelines (27). GDM increases the morbidity of the mother and baby in the index pregnancy, but also serves as an indicator of increased risks for subsequent type 2 diabetes and other metabolic disturbances (7, 8, 9, $10,28)$. Thus, the proper cost effectiveness of GDM screening is reported to be mainly based on identifying these risk groups and on the possibility to prevent or delay their onset (29). Therefore, it is probable that effective screening will be repaid in the future. However, this would require effective measures to prevent type 2 diabetes, starting from overcoming the low attendance rate of postpartum follow-up programs $(30,31)$.

It has been suggested that GDM diagnosis would predispose to delivery induction, instrumental deliveries, and caesarean sections with relative medical reasons $(2,32)$. In previous randomized controlled studies, however, the caesarean section rate has remained unchanged (5) or even decreased (33) in groups with active treatment of recorded GDM. In our study, the percentage of caesarean sections in GDM mothers increased significantly, which was consistent with the results of some earlier studies (2). At the same time the overall caesarean section rate remained similar while the caesarean section rate decreased in the control group. Our data do not allow us to distinguish the reasons for this tendency. Our population-based study reflects 'real-life' changes in treatments with relative medical indications in a natural setting more accurately than a randomized trial. Induction of labor has been shown to be increased by active treatment of mild GDM in one but not in another study $(5,33)$. In our study, induction of labor was found to have increased from 2006 to 2010, but this increase was similar in women with or without GDM.

In Finland, antenatal care is free of charge and is practically universally attended. It is obligatory for the delivery hospital to report every birth to the MBR. Therefore, the study population is unselected and virtually complete. The diagnosis of GDM was set according to recorded abnormal OGTT or initiated insulin treatment, 
which can be considered reliable and comparable during the 2 study years. Still, there were also some limitations in this study. For instance, our data did not allow us to define single risk factors during the study periods. We were thus unable to compare women who would have been screened because of risk factors in 2010 with women who underwent screening because of the comprehensive screening policy. Moreover, in an observational study it is difficult to distinguish between changes resulting from the new screening policy and time trends, i.e. changes that would have occurred anyway. However, the strongly statistically significant interactions between GDM and study year show that changes in characteristics such as maternal prepregnancy BMI and parity between the 2 study years were different in mothers with and without GDM, and argue for an effect of a policy change. While the risk factor-based screening was attended by $27.5 \%$ of women, 2 years after launching new national Current Care Guidelines, the amount of screened mothers was 51\% when the estimated amount of mothers who were supposed to undergo screening was $80 \%$. However, it takes time to reach full implementation, and we believe that the target will be approached in future years.

The change to a comprehensive screening policy led to a significant increase of GDM women, mainly with mild disease with diet treatment. They were also more often primiparous and had lower BMI levels. Caesarean sections were more concentrated in GDM mothers, while overall caesarean section rates remained similar. However, comprehensive screening did not perform better in diagnosing an essential risk group - women needing insulin treatment. Therefore, the optimal screening method for GDM remains controversial, although our study as a whole adds to accumulating evidence in favor of comprehensive screening. Further, the cost-effectiveness of a wide-scale screening should be further evaluated, with the increased pressures on maternal care balanced with possible improvements in perinatal outcomes.

\section{Declaration of interest}

The authors declare that there is no conflict of interest that could be perceived as prejudicing the impartiality of the research reported.

\section{Funding}

The study was supported by grants from Academy of Finland, Emil Aaltonen Foundation, Foundation of Pediatric Research, The National Graduate School of Clinical Investigation, Novo Nordisk Foundation, Pohjois-Suomen Terveydenhuollon tukisäätiö Foundation and Sigrid Juselius Foundation.
Author contribution statement

All authors (S Koivunen, E Kajantie, A Torkki, A Bloigu, M Gissler, A Pouta, $M$ Vääräsmäki) contributed to the design and conduct of the paper, critically reviewed manuscript details, and approved the final version.

\section{References}

1 Avalos GE, Owens LA, Dunne F \& ATLANTIC DIP Collaborators. Applying current screening tools for gestational diabetes mellitus to a European population: is it time for change? Diabetes Care 201336 3040-3044. (doi:10.2337/dc12-2669)

2 Liao S, Mei J, Song W, Liu Y, Tan YD, Chi S, Li P, Chen X \& Deng S. The impact of the International Association of Diabetes and Pregnancy Study Groups (IADPSG) fasting glucose diagnostic criterion on the prevalence and outcomes of gestational diabetes mellitus in Han Chinese women. Diabetic Medicine 201431 341-351. (doi:10.1111/dme. 12349)

3 Ignell C, Claesson R, Anderberg E \& Berntorp K. Trends in the prevalence of gestational diabetes mellitus in southern Sweden, 2003-2012. Acta Obstetricia et Gynecologica Scandinavica 201493 420-424. (doi:10.1111/aogs.12340)

4 Metzger BE. Long-term outcomes in mothers diagnosed with gestational diabetes mellitus and their offspring. Clinical Obstetrics and Gynecology 200750 972-979. (doi:10.1097/GRF.0b013e31815 a61d6)

5 Crowther CA, Hiller JE, Moss JR, McPhee AJ, Jeffries WS, Robinson JS \& Australian Carbohydrate Intolerance Study in Pregnant Women (ACHOIS) Trial Group . Effect of treatment of gestational diabetes mellitus on pregnancy outcomes. New England Journal of Medicine 2005 352 2477-2486. (doi:10.1056/NEJMoa042973)

6 Crowther CA, Hague WM, Middleton PF, Baghurst PA, McPhee AJ, Tran TS, Yelland LN, Ashwood P, Han S, Dodd JM et al. The IDEAL study: investigation of dietary advice and lifestyle for women with borderline gestational diabetes: a randomised controlled trial - study protocol. BMC Pregnancy and Childbirth 201212 106-2393-12-106. (doi:10.1186/1471-2393-12-106)

7 Pirkola J, Pouta A, Bloigu A, Miettola S, Hartikainen AL, Jarvelin MR \& Vaarasmaki M. Prepregnancy overweight and gestational diabetes as determinants of subsequent diabetes and hypertension after 20-year follow-up. Journal of Clinical Endocrinology and Metabolism 201095 772-778. (doi:10.1210/jc.2009-1075)

8 Ijas H, Morin-Papunen L, Keranen AK, Bloigu R, Ruokonen A, Puukka K, Ebeling T, Raudaskoski T \& Vaarasmaki M. Pre-pregnancy overweight overtakes gestational diabetes as a risk factor for subsequent metabolic syndrome. European Journal of Endocrinology 2013169 605-611. (doi:10.1530/EJE-13-0412)

9 Freire CM, Barbosa FB, de Almeida MC, Miranda PA, Barbosa MM, Nogueira AI, Guimaraes MM, Nunes Mdo C \& Ribeiro-Oliveira A Jr. Previous gestational diabetes is independently associated with increased carotid intima-media thickness, similarly to metabolic syndrome - a case control studyOliveira. Cardiovascular Diabetology 201211 59-2840-11-59. (doi:10.1186/1475-2840-11-59)

10 Pirkola J, Pouta A, Bloigu A, Hartikainen AL, Laitinen J, Jarvelin MR \& Vaarasmaki M. Risks of overweight and abdominal obesity at age 16 years associated with prenatal exposures to maternal prepregnancy overweight and gestational diabetes mellitus. Diabetes Care 201033 1115-1121. (doi:10.2337/dc09-1871)

11 Carpenter MW \& Coustan DR. Criteria for screening tests for gestational diabetes. American Journal of Obstetrics and Gynecology 1982 $144768-773$.

12 O'Sullivan JB \& Mahan CM. Criteria for the oral glucose tolerance test in pregnancy. Diabetes 196413 278-285. 
13 HAPO Study Cooperative Research Group , Metzger BE, Lowe LP, Dyer AR, Trimble ER, Chaovarindr U, Coustan DR, Hadden DR, McCance DR, Hod M et al. Hyperglycemia and adverse pregnancy outcomes. New England Journal of Medicine 2008358 1991-2002. (doi:10.1056/NEJMoa0707943)

14 International Association of Diabetes and Pregnancy Study Groups Consensus Panel , Metzger BE, Gabbe SG, Persson B, Buchanan TA, Catalano PA, Damm P, Dyer AR, Leiva A, Hod M et al. International association of diabetes and pregnancy study groups recommendations on the diagnosis and classification of hyperglycemia in pregnancy. Diabetes Care 201033 676-682. (doi:10.2337/dc09-1848)

15 Poyhonen-Alho MK, Teramo KA, Kaaja RJ \& Hiilesmaa VK. 50 gram oral glucose challenge test combined with risk factor-based screening for gestational diabetes. European Journal of Obstetrics, Gynecology, and Reproductive Biology 2005121 34-37. (doi:10.1016/j.ejogrb.2004.10.008)

16 Finnish Medical Society Duodecim. Current Care Guidelines for Gestational Diabetes. Helsinki, Finland: The Finnish Medical Society Duodecim, 2008. (available at: www.kaypahoito.fi)

17 Gissler M \& Shelley J. Quality of data on subsequent events in a routine Medical Birth Register. Medical Informatics and the Internet in Medicine 200227 33-38. (doi:10.1080/14639230110119234)

18 Gissler M, Teperi J, Hemminki E \& Merilainen J. Data quality after restructuring a national medical registry. Scandinavian Journal of Social Medicine 199523 75-80.

19 Pihkala J, Hakala T, Voutilainen P \& Raivio K. Characteristic of recent fetal growth curves in Finland. Duodecim; Lääketieteellinen Aikakauskirja 1989105 1540-1546.

20 Statistics Finland. Classification of socio-economic status 1989. Helsinki, Finland: Statistics Finland, 1989. (available at: http://www. stat.fi/meta/luokitukset/sosioekon_asema/001-1989/kuvaus_en.html)

21 Statistics Finland. Statistics on population structure. Helsinki, Finland: Statistics Finland, 2015. (available at: http://www.stat.fi/til/vaerak/ index_en.html)

22 Chevalier N, Fenichel P, Giaume V, Loizeau S, Bongain A, Daideri G, Brucker-Davis F \& Hieronimus S. Universal two-step screening strategy for gestational diabetes has weak relevance in French Mediterranean women: should we simplify the screening strategy for gestational diabetes in France? Diabetes \& Metabolism 201137 419-425. (doi:10.1016/j.diabet.2011.01.004)

23 Hayes L, Bilous R, Bilous M, Brandon H, Crowder D, Emmerson C, Lewis-Barned $\mathrm{N} \&$ Bell R. Universal screening to identify gestational diabetes: a multi-centre study in the North of England. Diabetes Research and Clinical Practice 2013100 e74-e77. (doi:10.1016/j.diabres. 2013.03.019)
24 Peltonen M, Korpi-Hyövälti E, Oksa H, Puolijoki H, Saltevo J, Vanhala M, Saaristo T, Saarikoski L, Sundvall J \& Tuomilehto J. Lihavuuden, diabeteksen ja muiden glukoosiaineenvaihdunnan häiriöiden esiintyvyys suomalaisessa aikuisväestössä Dehkon D2-hanke (D2D). Finnish Medical Journal 200661 163-170.

25 Metzger BE \& Coustan DR. Summary and recommendations of the Fourth International Workshop-Conference on Gestational Diabetes Mellitus. The Organizing Committee. Diabetes Care 199821 (Suppl 2) B161-B167.

26 Lu GC, Luchesse A, Chapman V, Cliver S \& Rouse DJ. Screening for gestational diabetes mellitus in the subsequent pregnancy: is it worthwhile? American Journal of Obstetrics and Gynecology 2002187 918-921. (doi:10.1067/mob.2002.126979)

27 National Institute for Health and Care Excellence. Diabetes in pregnancy. Management of diabetes and its complications from preconception to the postnatal period. London, UK: National Institute for Health and Care Excellence, 2015. (available at: http://www.nice. org.uk/guidance/ng3/chapter/1-recommendations)

28 O'Sullivan JB. Diabetes mellitus after GDM. Diabetes 199140 (Suppl 2) 131-135. (doi:10.2337/diab.40.2.S131)

29 Werner EF, Pettker CM, Zuckerwise L, Reel M, Funai EF, Henderson J \& Thung SF. Screening for gestational diabetes mellitus: are the criteria proposed by the international association of the Diabetes and Pregnancy Study Groups cost-effective? Diabetes Care 201235 529-535. (doi:10.2337/dc11-1643)

30 Lauenborg J, Hansen T, Jensen DM, Vestergaard H, Molsted-Pedersen L, Hornnes P, Locht H, Pedersen $\mathrm{O} \&$ Damm P. Increasing incidence of diabetes after gestational diabetes: a long-term follow-up in a Danish population. Diabetes Care 200427 1194-1199. (doi:10.2337/diacare.27. 5.1194)

31 Korpi-Hyovalti E, Laaksonen DE, Schwab U, Heinonen S \& Niskanen L. How can we increase postpartum glucose screening in women at high risk for gestational diabetes mellitus? International Journal of Endocrinology 20122012 519267. (doi:10.1155/2012/519267)

32 Moss JR, Crowther CA, Hiller JE, Willson KJ \& Robinson JS. Australian Carbohydrate Intolerance Study in Pregnant Women Group. Costs and consequences of treatment for mild gestational diabetes mellitus evaluation from the ACHOIS randomised trial. BMC Pregnancy and Childbirth 20077 27. (doi:10.1186/1471-2393-7-27)

33 Landon MB, Spong CY, Thom E, Carpenter MW, Ramin SM, Casey B, Wapner RJ, Varner MW, Rouse DJ, Thorp JM Jr et al. A multicenter, randomized trial of treatment for mild gestational diabetes. New England Journal of Medicine 2009361 1339-1348. (doi:10.1056/ NEJMoa0902430)

Received 16 March 2015

Revised 30 July 2015

Accepted 17 August 2015 